\title{
RISK ANALYSIS AND STRATEGIC PLANNING FOR MANAGING URBAN SECURITY
}

\author{
Leta Bardjieva MIOVSKA, MA \\ Institute for Security, Defense and Peace \\ E-mail: Ibardjieva@gmail.com
}

\begin{abstract}
The content of this paper has risk analysis and strategic planning for managing urban security in its focus. The comprehensive and systematic analysis of the risks and threats in urban environments, plays a pivotal role in ensuring the many dimensions of contemporary urban security. These risks and threats include hazards for the safety of the fundamental basic supplies, for uninterrupted function of the society, protection from natural disasters and threats from various sources, such as urban crime, terrorism acts, cyber attacks, mass migrations and other forms of urban security imperilment.

In order to achieve urban security, both the local aspect and case-specific solutions, as well as global trends have to be taken in consideration while formulating the assesment, planning and preparation of the urban security strategies. It is important to emphasize the role of the relevant institutions, both public and private in this process, their capabilities and level of synchronization in performing this function. The methodology of this paper includes methods of analysis of primary and secondary data in the relevant topic, quantitative display of statistical figures regarding this issue, qualitative analysis of the vertical and horizontal distribution of planning processes in the provision of urban security and comparison methods.
\end{abstract}

Key words: Urban, security, strategy, planning, management.

\section{Introduction}

The notion urban area refers to towns, cities and suburbs. The urban area includes the city itself, as well as the surrounding area, according to the definitions (National Geographic). Throughout the world, the dominant pattern of inter-state migration is from rural to urban areas. Urban areas are perceived as centers with more economic and social opportunities, while the rural areas are viewed as slower, peaceful places surrounded by natural landscapes. According to facts summarized by relevant statistical data, by the year 2030 , more than $60 \%$ of the global population will live in cities, and around 2 billion people in the world will live in slums ${ }^{41}$.

41 Another synonim for ghetto. Overcrowded urban area or district in the cities with lower social organization, poverty and insufficient infrastructure. https://www.merriam-webster.com/dictionary/slum (accessed 12.05.2019) 
These figures depict the greatness of this issue, having in mind that between $1 / 3$ and $1 / 4$ of the world population will lack proper protection from risks causing the "risk accumulation" effect.

The suburbs are a combination of the urban living and the closeness to the natural habitat of the people, because of the location of the suburbs - close to the countryside, and close to the flashing lights of the city. Urban resilience is defined as the capacity of the community, institutions, businesses, systems and individuals in a certain city to survive, adapt and overcome acute shock events and chronic issues which may occure. Resilince $s$ a concept of endurance, the ability to minimize vulnerabilities and maximise the adjustment and evolving from risks and hazards.

The risk accumulation is a sum of disaster risk caused by extreme natural hazards and the every- day risks catalyzed by human activities, and is specific for urban areas. In that manner, urbanization can be projected as an increase factor for hazards and an exposure of people and assets to modified risk patterns, and by that driving the disaster management in urban areas exceptionally heavy. In parallel, the strategic urban physical and security planning can simultaneously create innovative ways for risk reduction.

The term aggregated risk comprises the coincident, related or interconnected risk. Coincident pressuposes two risks which eventuate simultaneously but from unrelated causes. Related - two risks which eventuate because of a common cause. 2019).

Interconnected risks are related by their generic characteristics (Corporate Finance Institute,

Agregated risks often result with large impact, but are in certain cases incorrectly interpreted as black swan events (Rio Tinto 2012). The latest trends in strategic planning of the urban resilience and managing urban security signifies understanding the connectivity between the risks, and this trend is emerging from the insurance sector. Strategic urban planning in contemporary conditions has primarily the purpose to mitigate the shock events, so-called "the black swan" - events with very low probability but with a high impact, which are meant to evoke fear, to generate disorder, to cause damage and ultimately destroy the social order in a given society (Strategic Info). While analyzing the events in the urban areas related to these occurrences, it is evident that they are far more often than we are aware.

These events are securitizied and remain high in the agenda of the policy creators, governments, security experts, civic associations, etc. In the era of post 9/11, the scenarios of "what if" are no longer valid, they are replaced with "when, where" scenarios of likelihood (Davis 2019). When it comes to explanation of the urban areas risks, the Black swan theory was introduced by Nassim Nicholas Taleb (2008), which elaborates the notion, that has to have these three attributes:

1. An unpredictable event that counterpoises an outlier, an exception, exceeding beyond the realm of regular expectations, because the so far experience cannot point to its possibility

2. The event has an extreme impact and widespread ramifications and severe consequences

3. After the event has occured, the observers will assert and rationalized that it was in fact predictable and expected (known as the hindsight bias). 


\section{Securiaty}

Cities counterpoise the economic stream in a given country and are the core of the political, economic, financial and intellectual activities. Their expansion itself is a proof that if the risk management is well performed, the results are far-reaching progress and an improved level of security. These advances are achievable through economies of scale and the proximity of risk-reducing infrastructure and services, such as: provision for sanitation, drainage, waste collection, health care and emergency services, utilization of the derived hi-tech expertise and knowledge (UNDP).

\section{Risk Assesment and Strategic Planning}

When it comes to assessing a certain situation or foresee an event, it is necessary to answer how is the impact risk perceived? Or, how can the ability to identify and manage these risks be improved? It is important to take into consideration the unthinkable, or formulated differently - how bad can it be? Concrete examples are the collapse of the Twin towers of the World Trade Center in 2001, the Chernobyl disaster in 1986; the Christchurch massacre from 2019, as one of the latest black swan events which was not predicted and the authorities have not responded rapidly enough, due to the low probability they assessed, meaning: the low probability / high consequence risks can result from a number of low probability / high consequence causes, respectibly.

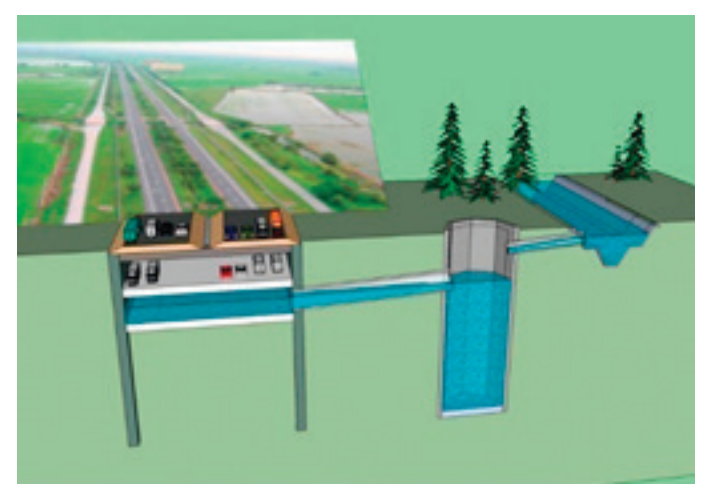

Figure 1: Multipurpose Underground Service Flood Tunnel System (MUSTS). Long Term Flood prevention Chaophaya Basin, Thailand. Source: https://www.tunnel-online.info/de/artikel/tunnel_2012-03_1419387.html 


\section{Securiatity}

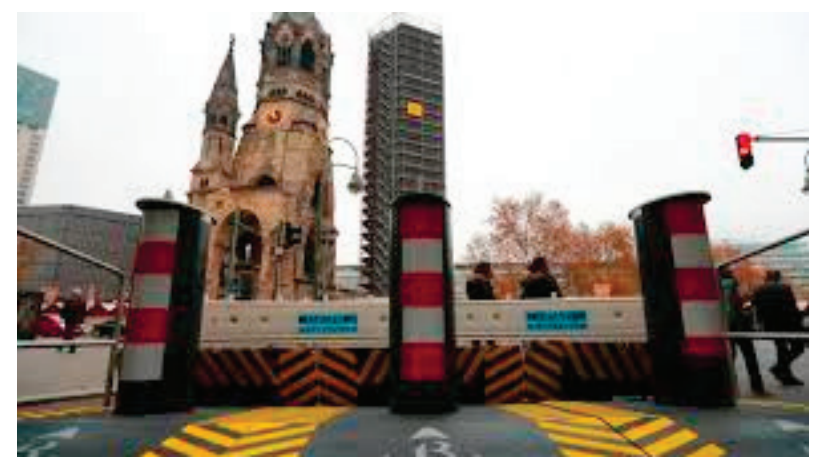

Figure 2: Berlin Christmas Market 2018 Terrorism Protection. Foto Reuters. Source: https:/www.magyaridok.hu/ kulfold/rendkivuli-biztonsagi-intezkedesek-a-berlini-karacsonyi-vasar-teruleten-3700697/

As a chronological retrospective, cities and urban centers were always facing and experiencing risks; many cities that have a long history and centuries old tradition endured and projected resilience while facing resource insufficiency, natural catastrophes and violence. The new challenges for the urban living and welfare in the 21st century described as global pressures on a city scale - including climate change, disease pandemics, economic oscilations, and terrorism threats demand appropriate set of measures which will be both effective and economic. The ratio of urban risk is increasing due to the number of people living in cities. Furthermore, risk can be also depicted as increasingly unpredictable due to the complexity of city systems and the uncertainty associated with many hazards - notably climate change.

These events had led to the development of the urban areas by the concept of smart growth, respectfully, a purposeful creation of the urban areas. This concept presupposes creation of communities less dependent on motor vehicles, recovery of old communities in the city central areas, more pedestrian areas, as well as city green spots or wilderness, organic farms and lakes. Due to the enormous amount of contemporary constructive materials in the urban areas, the rain and snow water is typically drained out and it cannot be collected on the paved ground. In these cases, the smart planning of urban city landscapes could introduce wetlands designed to filter and contain the waters from the rains, snows and storms, instead of the draining pipes and ditches.

The strategic planning and smart growth involves developing urban areas in harmony with the surrounding geography. City planners, architects and engineers construct structures that blend in with their natural habitat and use natural materials. And there is also the trend of preserving and maintaining the green areas in the urban areas and planting trees There is also a move toward preserving and maintaining more green areas and planting more trees in urban areas. Urban planners more often incorporate parks within the cities and suburbs while designing the urban landscape. It is a concept that embraces aesthetics and design and practical solutions following the natural course, in that way reducing and preventing natural disasters and climate change. 


\section{Managing Natural Disasters - Assesment and Contingency Planning}

It is without doubt evident that in present times the natural disasters are by default accelerated and caused by human activity. In that direction, some of the human behavior which contributes toward degrading the environment and increases the odds for a major incident in urban areas can be outlined as lack of building codes and zoning laws in the political domain, population increase as an anthropoligal phenomena, migration to urban areas as an economic and social trend, and settlement in high-hazard areas as a result of the drastic division of wealth and emergence of extreme poverty on one side and luxurious life style on the other.

When discussing about urban strategies and planning in order to achieve and maintain resilience, the infrastructure grid is a crucial element in every urban contingency plan. The planning of the infrastructure security and protection presupposes locating the systems on a safe position, structure strengthening and contingency planning in cases of damage, disruption or failure during and after disaster events. Physical infrastructure prone to vulnerable effects of natural disasters include:

- Older residential complexes with poor maintenance in dense populated places which have features such as overcrowding, extension and alternation

- Structures built without abiding standards and regulations and objects built before a standard or a regulation had been introduced

- Unplanned and suburbanized informal marginal settlements in hazard prone areas

- Buildings with new materials but with low quality construction and design

- Concentration of control and communication centers in a small radius area

- Inaccessible and insufficient health facilities which are not capable to manage mass casualty incidents in terms of disaster

- Low building standards community facilities incapable to be utilized as emergency shelters

- Poorly projected roads, railways, bridges, dams and culverts which, if collapsed would cut off access for the emergency services for evacuation and aid provision

- Narrow streets that are easily blocked by debris in terms of catastrophe and emergency and are prone to traffic stalls, which can make emergency assistance more difficult

- Open and ruptured water supplies networks which are prone to pollution and disease

- Poor sewage management resulting in flooding and disease spread

- Unreliable electricity grids

- Unsafe gas supply grids which can result in fires

- Poor industrial management causing in leaks, pollutions, hazardous materials resulting in fires, explosion and other disasters (City Resilience Index).

An inevitable fact that needs to be pointed out that even in cases when strategies of urban risk assessment do exist, the governments on a central and local level face challenges in regard of the development, implementation and maintenance of the risk management plans (World Bank 2010). The following are the contributing factors that need to be facilitated in direction of sustainable long term strategic planning for urban resilience: 


\section{Seccurity}

- Professional, expert and intellectual understanding of the concept of climate risks: in many governments on a central and local level, there is a comprehension insufficiency for the existing sources of risk and potential impact of climate change. In addition, the lack of standardized methodology for conducting risk assessments exacerbates this shortcoming and can contribute to risk development, especially in urban areas with uncontrolled growth and informal settlements which need additional attention.

- Building institutional capacity and financial resources: municipalities and local authorities do not always have the necessary resources at disposal and their allocation is a procedure that sometimes exceeds the optimal response period in addressing urban challenges and risk prevention. Under these circumstances, climate change and disaster contingency planning are not always high on the agendas, especially if the gross portion of the budget is allocated for salaries and basic activities. Additionally, city managements need technical and financial assistance in enhancing institutional capacities to assess and respond to disasters more effectively.

- Introduction of standard procedures and protocols for risk and disaster management and climate change adaptation in city planning.

- Performance measuring: monitoring the performance of the implementation and facilitation of the plans and improvement of the exchange of examples of best practices among cities. Introduction of systematic benchmarking that will allow recording progress or shortfalls (Levander et al, 2015).

Risk assessments and reduction measures for specific foreseeable risks shall continue to play an important role in urban planning. Additionally, cities and the local government need to ensure that their development strategies and investment decisions enhance, rather than undermine, the city's resilience, which was expressed through numerous unfortunate events, which happened, as the case of Skopje and Tetovo in August 2016 and August 2015, respectibly. Earlier, the flood in the Pelagonija region in February 2015 showed the wide spread pattern, that according to the UNDP office in Skopje, illustrate the Western Balkans as one of the most flood-prone and potentially disastrous regions in the world. But these facts can be changed and they are not definite or inevitable.

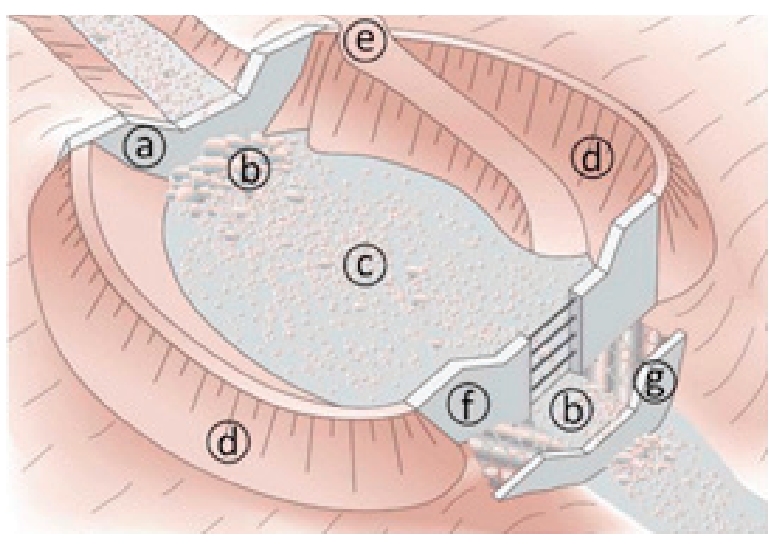

The most appropriate response is of course, prevention and investing in protective infrastructure and smart planning that will protect lives and property (UNDP).

Figure 3: Torrential Check Dam. Geosciences Source: https://www.mdpi.com/2076-3263/9/2/64

In that direction, a rational and logical proposition is for the governments, donors, investors, policy-makers, and the private sector to jointly support and plan 
for more resilient cities, by developing a platform for common understanding of what constitutes a resilient city and how it can be attained (City Resilience Index 2014).

Risk analysis and assesment in urban centers for managing natural disasters had shown that environmental threats are a main cause of low health quality, injuries and premature death in many urban areas. It is important to emphasize that many of these hazards are likely to occur in rural areas as well, but their magnitude can become especially threatning in densely inhabitated urban areas with thick architecture. In the low income countries the people living in these cities and urban districts these potential threats numbers are even bigger. These risks may be:

- Biological (diseases caused by poor sanitation or unclean water, or combined)

- Chemical (toxic water polutants, air pollution from uncontroled fires, chemicals and industrial processes, traffic, poor waste and toxic waste management)

- Physical (earthqauckes, floods, fires, extreme weather temperatures, droughts, soil erosion caused by deforestation, cyclones, etc.)

- Social and political - politically inflicted violence, social unrest and conflict, organized crime, gangs and terrorism.

Predictions illustrate a strong likelihood for major urban disastrous events in the future as well. Already, many countries and cities in the world are located in tectonic zones (potential earthquake areas) and it is a case of both poor and wealthy countries. Countries and cities located on the coastal lines are additionally prone to tsunamis and cyclones, and as they magnify they impose a hazard for locations such as deserts, hillsides and low-lying terrains. Unplanned or poorly planned urbanization and urban growth can increase the imbalance of ecosystems which naturally contribute toward resilience (HPN 2019).

As a conclusion for this segment of the comparative depiction of the paper, it could be stated that on every corner, the world becomes more urbanized every day. In parallel, the climate changes, and many cities, both rich and poor by statistics are exposed to these trends and threats and the new reality is equivalent to never ending crisis - regardless if it is a tsunami, a fire, a flood, a terrorism attack or uncontrolled migrant flow.

\section{Terrorism Resilience and Urban Planning}

The classical security measures of increased surveillance systems, satelite and video movement detection, activity monitoring and purchasing the latest technological versions of equipment with high price for the law enforcement and the armed forces in combating terrorism threats, are tactics which are accompanied by contreoversy, since these measures tackle issues of civil rights violation and relienace on very sophisticated equipment that does not yet exist on the market.

Utilizing urban designs in order to achieve higher urban security has an increased level of advocacy by many involved and concerned stakeholders. It is due the fact that these alterations are easy to implement and can contribute toward safety even if the urban area is not directly prone to terror attacks, especially with fast moving vehicles, as shown by latest trends. 
What is significant to emphasize is that the tactics of using driving vehicles as a manner of performing terrorist attacks has a genesis since 2010, a tactic promoted by Al qaeda, later followed by ISIS affiliates. It is a specific tactic that does not even require the basic military or any other training style capabilities, and a regular vehicle is often overlooked by the security measures installed untill it is too late. In that direction, the efforts of separating trajectory lines of motorized vehicles and pedestrian and cycling spaces takes place by security experts and urban planners while arranging the set of measures.

The weakest spots in urban areas exposed to terrorism threats with driving vehicles can be divided by the following description:

i. Poorly separated public and private activities in a given urban space

ii. Numerous building with identical function that are not redistributed in a surrounding area

iii. Accessible points to the building or the facility are not minimalized

iv. The targeted object is surrounded by open space

v. No police or security presence on the site at a given time interval

vi. Minimal distance between objects and site boundaries

Therefore, grass-root activitsts, experts as well as urban planners promote a concept of city design which will simultaneously incorporate artistic instalations, urban infrastructure decors and trees as an effective threat to the ever-growing trend of threats caused by terrorism acts, most recently the trend of driving motor vehicles as a weapon of choice into crowded areas (Matijosaitiene, I., Petriashvili, A, 2017).

This approach features distinctive separation of vehicle traffic, pedestrian trails and cyclist paths with physical barriers that prevent speeding vehicles to plunge into the crowd. This combination of urban equipment instalation that has both functional and protective function is the most embraced concept for urban planning which incorporates the contemporary life style and surrounding with security measures. The lorry attacks in Nice, France from 2016 when more than 80 people have lost their lives, the Berlin lorry attack on the Christmas Market in 2016, claiming 12 casulaties, the Manchester arena bombing in 2017, which took the lives of 23 people (including the attacker), as well as numerous other attacks throughout European urban areas have led to increased need for legislative changes which counterpoise stricter and more severe regulations, as well as planning of the urban physical space which will eventually prevent or at least alleviate the consequences of such events. The Berlin Senate for instance, had come up with solutions for introducing terra blocks as additional security measures (De Local 2018).

Yet in addition to the physical security measures, experts and general standpoints point out the role of the intelligence services of Germany and France for the specific incidents, but other countries' intelligence agencies and their intel sharing and coordination, which is without doubt overwhelmed with data on possible perpetrators (Blaxland, 2016). It is important to emphasize that if a simple analysis is made on the terrorist attacks in the urban areas, regardless whether they occurred in European capitals or in cities in the Middle East, they most likely occurred 
in areas that are very crowded with people. Airports, bus, train and subway stations, schools, universities, kindergartens, religious sites, shopping malls, markets, stadiums and events are especially vulnerable to these hazards, and counterpoise high-risk situations. Since the fundamental aim of the terrorist acts in theory and reality is causing as much casualties, damage and attention as possible. Here, it is important to note that beside the classical and most frequent suicide attacks with bombs and improvised explosive devices, and mass shooting execution stile murders (often followed by suicide), there is an increasing trend in the number of attacks with vehicles (trucks and lorries) and low technology attacks with knifes.

Basically, the planning of the risk management in urban areas for the authorized institutions on an operative level and on a strategic and political governmental and legislative level is contingency planning and resilience continuity by analyzing related causes and taking preventive measures in "expecting the unexpected".

Contemporary urban life style is primarily characterized by the high demand for uninterrupted supply of goods and services (e.g. electricity, internet access, water supplies and waste disposal, public transport and infrastructure, emergency service, etc.). This trend is more drastically expressed in urban areas. In this direction, from an explanatory, hypothetical aspect, it is easier to assess the individual components in a given urban system, e.g. the quality and the resilience of a building, power supply grids, etc., than it is to assess a multi connected and complex sum of assets, processes and systems of the involved actors and their correlation as physical structures and human behavior.

In that direction, threatening events and disasters will definitely inflict damage and loss of critical infrastructure systems, which can have long range consequences even for the developed urban centers. In this regard, the local, respectively, municipal or city management has a crucial role in providing political solutions, granting adequate amounts of resources and maintaining infrastructure systems and facilities in order to implement comprehensive and multifaceted measures for an optimal functioning.

Given the various nature and purpose of the numerous actors in an urban area, including institutions, organizations, companies, enterprises, etc., in combination with the natural surrounding and eco system, as well as the current built-in circumstances, culture, connectivity, the urban area can be defined as a inter and co-dependent comprehensive system. Meaning, people need power grids and electricity supply to perform the every-day tasks in their work places; hospitals need water sanitations in order to maintain hygiene standards; the transportation system is necessary for moving resources and goods. Therefore, the disruption of just one sub component of the critical infrastructure system will certainly cause a domino effect and multi layered consequences. These variables lead to a conclusion that while preparing a strategic plan for urban resilience and an integrated approach toward preventing and mitigating urban risks and hazards several aspects need to be covered (City Resilience Index).

Based on data available on the online sources, as well as official documents by formal institutions and decision makers, scientific analysis and think tanks, when planning for a resilient urban area in contemporary setting, the indicators are divided in four categories: 


\section{Seccurity}

1. The wellbeing and health of the people (citizens)

2. Environment and infrastructure (spatial context)

3. Economy and society (order)

4. Strategy and leadership (skills and capacity)

The indicators that counterpoise a milestone in shaping the plans and comprise the above listed four categories are the following:

i. Indicator for the extent of met needs and minimum human vulnerability

ii. Access to education, skills, employment, finances, savings ability, social welfare, services and diverse livelihoods

iii. Guarantee for security and safeguarding human life and health, functioning facilities and services and emergency management

iv. Sense and culture of collective identity and support mechanisms, social integration and community networks of engagement

v. Security and social stability incorporating law enforcement, crime prevention, rule of law and civil protection

vi. Sound financial management, stabile financial resources and contingency funding, diverse revenue flows, business investments

vii. Minimal physical exposure to vulnerability by sustainable environmental policies, proper infrastructure, physical planning of the land use and implementation of the regulations

viii. Critical infrastructure systems consistency as indicated by a proactive management and diverse provision in parallel with preserving the eco system and infrastructure contingency planning

ix. Transportation mobility and reliable communication grids provided by diverse sources and multimodal transport systems, security of ICT systems and contingency planning

x. Government, business and civic management and leadership with effective outcomes indicated by trusted representatives, multilevel consultations and fact based decision making

xi. Capability of the involved stake holders expressed through available information, latest updates on specific topics and empowered organizational capacities in order to grasp the most beneficial alternative

xii. Integrated strategy planning and development for an integral perspective and regular revision and update on a cross-departmental level and working groups.

\section{Conclusion}

The aim and the scope of this paper is to identify security issues regarding the urban strategic security planning for managing urban disaster (natural or man-made) resilience, as well as terror attacks in urban areas and asses the answers adapted to respond to them. In accordance with the hazard or the occurred event, pertinent responses are developed to prevent mass casualties and long-term consequences that affect the quality of well-being, the economic per- 
formance, political capacities and security levels in the community. Each urban area has specific features that need to be taken into consideration.

In parallel with the traditional, classical actors in the securitization process: politicians, police, military, intelligence and private security personnel, urban planners, spatial architecture and environment professionals are also taken into account in the latest trends of blending public interests and security aspects in the delivery of creative solutions for prevention of such catastrophic events as terror attacks. Since security risks have a complex feature, and as they incorporate interconnected aspects, their definition and management may be scoped by various rationalities and value systems. The most embraced approach toward tackling the issues of the complex security setting is found to be the urban resilience as an umbrella concept, comprised by a holistic response by policy makers and institutions.

\section{References}

1. Brunetta, G., Caldarice, O., Tollin, N., Rosas-Casals, M. (2018): Urban Resilience for Risk and Adaptation Governance: Theory and Practice. Springer International Publishing.

2. Dickson, E., Baker, J., L., Hoornweg, D., Tiwari, A. (2012): Urban Risk Assessments: An Approach for Understanding Disaster and Climate Risk in Cities. Washington DC, the World Bank.

3. Ducaru, S. (2019): Black Swans on the Eastern Flank. IOS Press.

4. Grant, B., and Yang Liu, C. (2018): Metropolitan Governance in Asia and the Pacific Rim: Borders, Challenges, Futures. Springer Nature Singapore.

5. Huang, G., Shen, Z. (2019): Urban Planning and Water-Related Disaster Management. Kanazawa City, Japan. Springer Nature.

6. Lucini, B.: The Other Side of Resilience to Terrorism (2017): A Portrait of a Resilient-Healthy City. Cham, Switzerland. Springer,

7. Pasman, H., Kirilov, I., A. (2007): Resilience of Cities to Terrorist and Other Treats. NATO Public Diplomacy Division, Moscow, Russia. Springer.

8. Sayers, P. (2012): Flood Risk: Planning, Design and Management of Flood Defense Infrastructure. Technology and Engineering. ICE Publishing.

9. Seo, N., S. (2019): Natural and Man Made Catastrophes: Theories, Economics and Policy Designs. Muaebak Institute of Global Warming Studies. Seoul, South Korea. Wiley \& Sons.

10. Serre, D., Barroca, B., Laganier, R. (2011): Resilience and Urban Risk Management. Boca Raton, CRC Press, Taylor \& Francis Group.

11. Бакрески, 0., Кековиќ, 3., Стефаноски, С., Павловиќ, С. (2016):Планирање и процена на ризик во функција на заштита на лица, имот и работење. Скопје, Комора на Република Македонија за приватно обезбедување.

12. Бакрески, 0., Милошевска, Т., Алчески, Ѓ. (2017): Заштита на критичната инфраструктура. Скопје, Стеда Графика. 